Rev. Soc. cient. Parag. 2021;26(1):4-5

https://doi.org/10.32480/rscp.2021.26.1.4

\title{
EDITORIAL
}

\section{0 años de la Revista y de la Sociedad Científica del Paraguay}

Alocución del Dr. Herib Caballero Campos por los 100 años de la SCP el 9 de enero de 2021 frente al monolito de Andrés Barbero.

La Sociedad Científica del Paraguay se conformó un día como hoy, pero de 1921, en la que la señera figura del doctor Andrés Barbero quien entonces tenía 43 años decide junto a varios de sus colegas y amigos la conformación de una asociación para la difusión de las ciencias físico-naturales.

Debemos recordar que este interés particular del doctor Barbero estaba condicionado por su formación de farmacéutico y de médico. Barbero quien ese entonces ya había enfrentado a la temible pandemia de la Gripe Española ocupándose de dirigir la Dirección de Higiene y Asistencia Pública estaba preocupado por que la ciencia se difunda en el país, un hombre culto y formado como él entendía que el atraso en que estaba sumido el Paraguay solo podía ser superado con la investigación y por el camino del conocimiento.

Cuando se produce la fundación él estaba más que atareado con el encargo que le había puesto su profesor, vecino y amigo el presidente Manuel Gondra, otro paraguayo destacado e ilustrado, Barbero desde 1920 se desempeñaba como Intendente Municipal de Asunción, y estaba bregando por la higiene de los mercados, por el ordenamiento de la ciudad y otros ingentes problemas que le acuciaban permanentemente, pero aun así decidió junto a otros ilustrados paraguayos y extranjeros residentes en el país que era necesaria una institución como la Sociedad Científica del Paraguay.

Aquella calurosa mañana de enero de 1921 le acompañaron en su decisión médicos como Gerardo Laguardia, Luis Migone, el farmacéutico Pedro M. Rodríguez, el economista Rodolfo Ritter, el agrónomo Leopoldo Benítez, los químicos Pedro Bruno Gugiari, Gustavo Crovato, los botánicos Karl Fiebrig, Arnoldo de Winkerield Bertoni, Guillermo Tell Bertoni, el entomólogo Pedro Jorgensen, abogados e intelectuales como Manuel Domínguez y Adolfo Antunez acompañados del profesor Marcial Bordas, Manuel Crosa y Juan Ángel Benítez. 


\section{Rev. Soc. cient. Parag. 2021;26(1):4-5}

En trazos elegantes, con términos sencillos pero contundentes, en unas hojas que hoy cien años después toman un color ocre está la voluntad de estos hombres de ciencia de constituir una asociación que tenía que difundir la ciencia, publicar una revista científica y buscar más adherentes a la causa del conocimiento que ellos emprendieron.

Por esta institución han transitado hombres y mujeres que tuvieron un punto en común, la convicción de que solo el conocimiento puede generar nuevas oportunidades y mejor calidad de vida a las personas y por ende a las sociedades.

A lo largo de las décadas nos han precedido figuras emblemáticas de las ciencias en el Paraguay, figuras que no tenían las posibilidades de financiamiento o de contactos con la comunidad científica internacional, aun así con otras herramientas no cejaron en su esfuerzo por lograr desarrollar sus actividades en favor de la investigación.

El hecho que estemos hoy conmemorando este magnífico aniversario es la ratificación de la voluntad y el legado de aquellos 17 profesionales que decidieron que en Paraguay era posible hacer ciencia a pesar de las adversidades y las inestabilidades propias de la época y a la vez es el peso del compromiso de continuar acrecentando las oportunidades para las nuevas generaciones de investigadores que se están formando en las universidades y centros de investigación tanto en nuestro país como en el exterior, con la esperanza y la convicción de que no hay otro camino.

Para concluir quisiera terminar esta breve alocución mencionando que, en la Asamblea General del 22 de junio de 1951 en este mismo edificio, se rindió un homenaje al entonces recientemente fallecido doctor Barbero refiriéndose a él como "alma y nervio" de la Sociedad Científica, durante las 3 décadas que duró su presidencia.

¡Eterno honor y gratitud al Doctor Andrés Barbero y en su persona a los fundadores de la Sociedad Científica del Paraguay!

Dr. Herib Caballero Campos 